\title{
Emerging and Re-Emerging Viral Diseases: The Case of Coro- navirus Disease-19 (COVID-19)
}

\author{
Gedif Meseret Abebe* (D) \\ Department of Biology, College of Natural and Computational Science, Wolaita Sodo University, Ethiopia
}

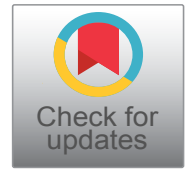

*Corresponding author: Gedif Meseret Abebe, Department of Biology, College of Natural and Computational Science, Wolaita Sodo University, Wolaita Sodo, Addis Ababa, Ethiopia

\begin{abstract}
Infectious viral diseases are the never-ending challenge that can emerge or re-emerge in unpredictable regions and at unpredictable times. Human beings are facing an intractable problem in unexpected time and place due to these viral diseases. Human, ecological, and viral related factors are the contributing factors in the emergence or re-emergence of viral infectious disease. Travel, mass gathering, urbanization, fragile or deteriorated health systems, weak disease surveillance system, limited laboratory diagnostic capacity, war, migration, poor hygienic practice, illegal animal trade, hunting and eating infected animals are among human-related factors that contribute in emergence or re-emergence of viral infectious disease. Deforestation, climate change, invasion of animal habitats, the building of dams and intensive agricultural practice are contributing factors to the emergence or re-emergence of viral infectious disease. The last but not least risk factor for emergence or re-emergence of infectious viral disease is the virus-related factors. RNA viruses are deadly pathogens since they are evolving rapidly in any hostile conditions and exhibit error-prone gene replication. Mutation, reassortment, and recombination attributed to high evolution rate. Among many RNA viruses, coronaviruses are enveloped, helical with large, positive sense, single-stranded RNA genome, and contain clubshaped surface proteins called spikes. Among many coronaviruses, the current emerged coronavirus disease-19 (COVID-19) can be considered as an "inferno" which aims to damage human beings irrespective of wealth, educational status, color, race, gender, religion, and class. This newly emerged virus has a detrimental impact on the economy, health, tourism, social interaction, education, religion, labor, markets, transportation, and human freedom, and in general, every sector is disrupted by COVID-19. Therefore, the aim of this review article is to provide an overview of emerging and re-emerging viral diseases, contributing factors, and a brief overview is also given to coronaviruses with especial emphasis to COVID-19.
\end{abstract}

\section{Keywords}

Emerging or re-emerging viral diseases, Contributing factors, Coronaviruses, COVID-1

\section{Introduction}

Although considerable progress has been made in the area of medical sector, the emergence or re-emergence of novel pandemic viruses remains an enduring problem in human health $[1,2]$. Infectious viral diseases are never-ending challenge that can emerge or reemerge in unpredictable regions and at unpredictable times [3]. An emerging viral disease is newly evolved, or newly recognized or have not been observed previously within a population or geographic location $[3,4]$. Re-emerging viral diseases are resurgence or recurring outbreaks for a significant part of the population, after a previous decline in incidence [5]. Viruses such as Severe Acute Respiratory Syndrome-associated coronavirus (SARS-CoV), Middle East respiratory syndrome coronavirus (MERS-CoV), human coronaviruses (229E, OC43, HUK1, NL63) [6], Avian influenza A(H7N9), and Ebola are examples of emerging viruses which have been evolved in different periods [3,7-9]. Among many human viruses corona viruses are known to be involved in more serious respiratory diseases, such as bronchitis, bronchiolitis or pneumonia, especially in young children and neonates, elderly people and immune-suppressed patients [6]. The recently emerged COVID-19 is a good example that scourges human health and specifically targets the above mentioned vulnerable segment of population. The continued emergence or re-emergence of such viral diseases have a detrimental impact on health, eco-

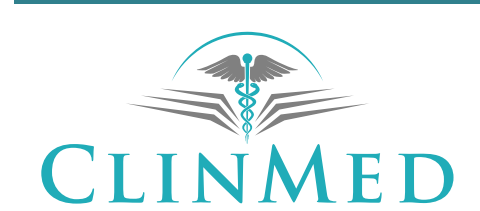

INTERNATIONAL LIBRARY
Citation: Abebe GM (2020) Emerging and Re-Emerging Viral Diseases: The Case of Coronavirus Disease-19 (COVID-19). Int J Virol AIDS 7:067. doi.org/10.23937/2469-567X/1510067

Received: May 15, 2020: Accepted: June 27, 2020: Published: June 29, 2020

Copyright: (c) 2020 Abebe GM. This is an open-access article distributed under the terms of the Creative Commons Attribution License, which permits unrestricted use, distribution, and reproduction in any medium, provided the original author and source are credited. 
nomy, social security and stability worldwide $[3,10,11]$. Newly emerged pathogens pose an intractable problem due to scarcity of knowledge and experience [12]. Since emerging viruses are new for that specific population or geographic area, information related to mode of transmission and replication, preventive methods, epidemiology, reservoir-host interaction, developing vaccine or antiviral drug might be scarce or difficult to understand within a short period. The same is true for the newly emerged COVID-19 which costs lives of millions because of lack of vaccine or antiviral drugs. Perhaps this pandemic may continue to sporadically pop up for many years and take lives of citizens until vaccines are discovered. The emergence of novel human pathogens and re-emergence of different diseases have attracted global concern and attention [13]. For instance, the current coronavirus disease-19 (COVID-19) was evolved at Wuhan city is now expands like wildfire which aims to damage human beings irrespective of wealth, educational status, color, race, gender, religion, and class. Therefore, "all human beings are in the same boat". This newly emerged virus has an impact on the economy, health, tourism, social interaction, politics, education, religion, labor, entertainment, sport, markets, hotels, transportation and human freedom and in general the emergence of COVID-19 disrupts these and other social functions. Additionally, the newly emerged viral disease may create panic within a community which leads instability. Therefore, the aim of this review article is to provide an overview of emerging and re-emerging viral diseases, contributing factors, and a brief overview is also given to coronaviruses with special emphasis to COVID-19.
Factors That Contribute in the Emergence or Reemergence of Viral Infectious Diseases

Knowing the contributing factors for emergence or re-emergence viral infectious diseases is the forefront step in mitigating the problem by tracing mode of transmission, suggesting the preventive and controlling methods, searching and identifying reservoirs of infection. As reports indicated human, environmental, ecological and viral factors are the main contributing factors in the emergence and re-emergence of viral disease $[4,14]$. These human, environmental, ecological and virus-related factors play a critical role in perpetuating novel emerging viruses. Additionally, changes in vector populations, in human association with reservoir hosts and appearance of new viral variants that are more efficiently transmitted are associated with emerging viruses [15]. As Bedford, et al. reported epidemics will become more serious, frequent, complex, harder to prevent and contain in rapidly changing ecology, urbanization, climate change, increased travel and fragile public health systems [16]. Hence, the new and recurring diseases will continue to emerge because of these demographic, ecological, anthropogenic, viral and host related factors. Thus, tracing and knowing the contributing factors in emergence and re-emergence novel pathogens is cornerstone for controlling and making global or country-based decisions. But if we are too late to make decisions, then the pathogens will spread as an inferno. COVID-19 is a good example for the crisis we are facing right now.

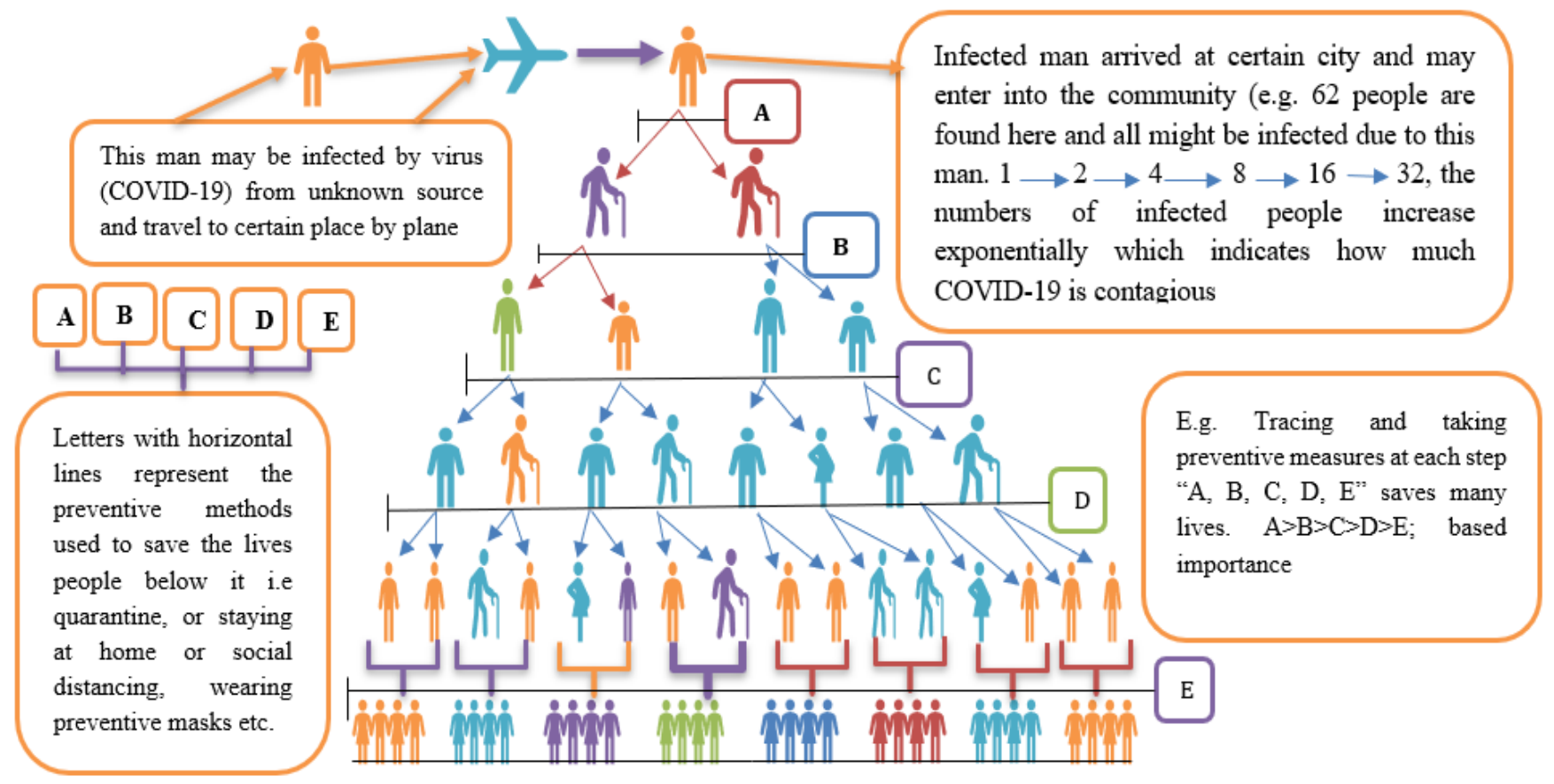

Figure 1: Transmission tree of COVID-19 within a community through global or local travel. 


\section{International and domestic travel}

International and domestic travel is a critical factor for emerging disease spread between countries (Figure 1). Global travel has had an effect on the emergence, spread of pathogens and the economic stability of societies [17]. For instance, the previously emerged SARS-associated coronavirus (SARS-CoV) in 2003 was spread to different countries through this mechanism [14]. Now history is repeating itself, COVID-19 emerged at Wuhan city and spread to different countries through international and domestic travel. This was the critical step to control the spreads of this virus. In support of this notion, Figure 1 is a good example that shows how one person coming from somewhere else becomes a health problem for 62 people (Figure 1). As indicated on Figure 1 , preventive methods taken at " $A$ " is the forefront and most important among other methods. Similarly, if the global community were integrated to halt the spreads of COVID-19 at its origin, then this much death toll couldn't happen. Therefore, the key to control of any pandemic is early identification and rapid response [18]. But any delay in detecting, surveillance and applying preventive and controlling measures can open a door for rapid spreads of pandemic such as COVID-19 within a short period of time. Due to its rapidity of spreads and global coverage, COVID-19 has rapidly acquired a pandemic status affecting almost all populated areas of the planet [19]. Therefore, controlling such widely spread pandemic is as difficult as controlling an inferno. This pandemic viral disease did not consider any border [20] and "did not seek any permission to travel". Therefore, to prevent the spreads of this pandemic countries restrict international flight but grounding international and local flight was issued after importing COVID-19. On the other side, this decision devastates the aviation sec- tor and becomes a cause for the recession of the global economy as well.

\section{Fragile healthcare system}

Fragile health systems alongside increased population mobility, rapid urbanization, climate change, weak surveillance and limited laboratory diagnostic capacity, and increased human-animal interaction are the main risk factors that contribute in the emergence and rapid spread of epidemic diseases [3,4,9,17,21-25] (Figure 2). A similar report revealed that deterioration of the public health systems, environmental changes, ecosystems disturbance and socio-economic recession are main contributing factors for emergence and re-emergence of infectious diseases [26]. Fragile and unprepared health system across the globe contributes to transmission during recent epidemics of Severe Acute Respiratory Syndrome (SARS) and Middle East Respiratory Syndrome (MERS) [27]. If lessons were taken from such previous incidents, then this much death causalities couldn't happen from the recent pandemics (COVID-19). It is possible to say that most countries especially developing nations are still living with fragile health system. A trusted witness for this idea is COVD-19 which reveals their internal gaps and failures on health sector. The other critical factor is disease surveillance systems which can be considered as "compass" that can provide information about disease incidence, manifestation, severity, etiological characteristics of the disease and their distributions [2]. That is why Lee said that Surveillance systems are the eyes of the health system and without them the health system would be blind [28]. Morse reported that development of effective, interconnected systems of infectious disease surveillance is essential to our survival [18]. However, weak surveillance system and limited laboratory facilities paves ways for the emergence or

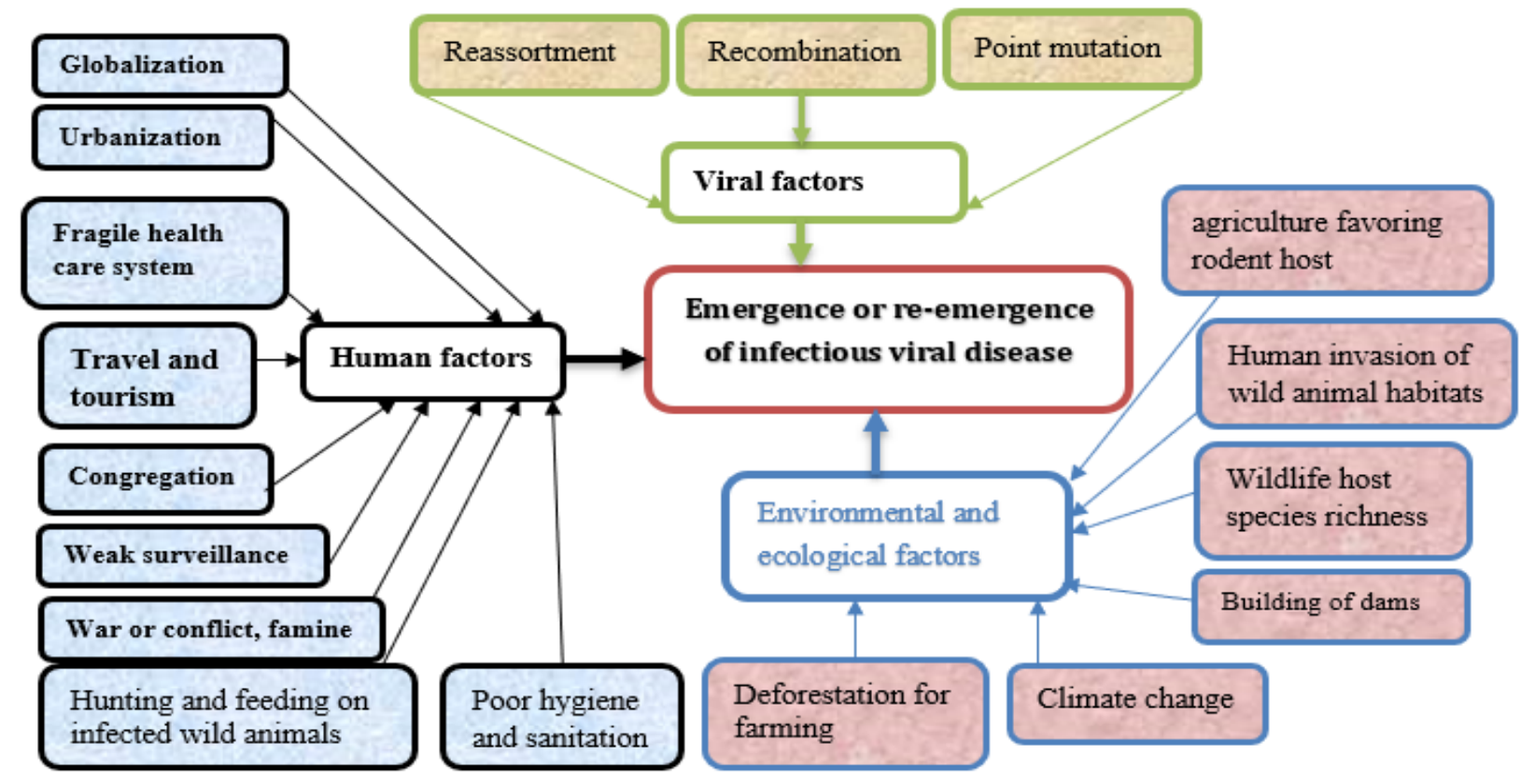

Figure 2: A glimpse of factors that contribute in emergence or re-emergence of viral disease $[3,4,9,17,21-24]$. 


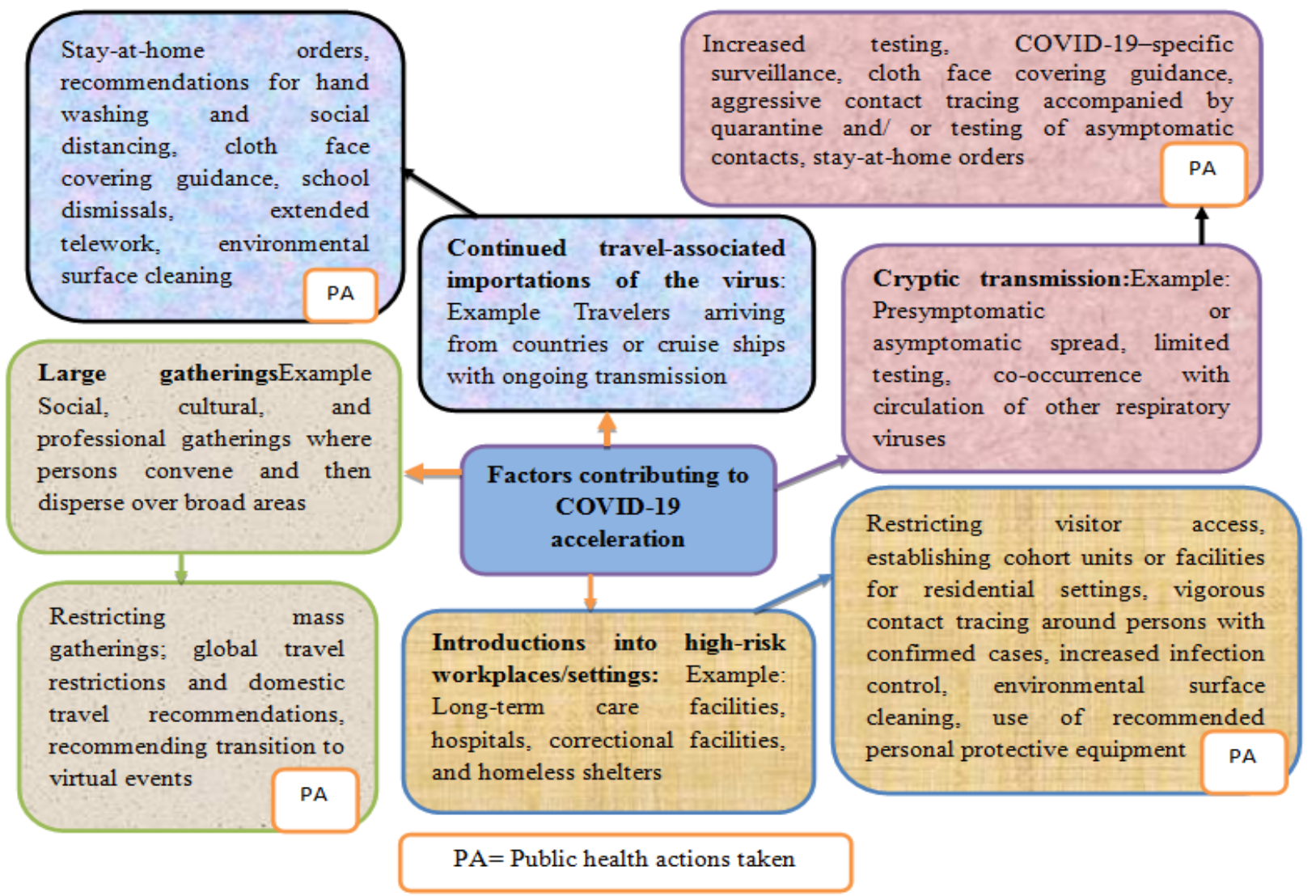

Figure 3: Specific examples of factors contributing to COVID-19 spread and corresponding public health actions taken in United States, January-April 2020 [30].

re-emergence of infectious disease. As mentioned previously mentioned COVID-19 showed the global health systems are not sufficient enough to handle such kinds of pandemics which will be an assignment for the global community. Especially, COVID-19 becomes a big fear for developing nations where there is a fragile health system, inadequate hospitals, medical tools, health professionals and other facilities. COVID-19 which was erupted unexpectedly becomes a critical challenge for unprepared global health system. Therefore, this is the right time to learn a lesson and fill our gaps on health system and get ready for the next challenge.

\section{Urbanization and population mobility}

Heedless mobility in crowded areas like in markets, bus stations, touristic areas, beaches and in other cluttered areas is the best means for spreading emerging viral diseases. For example, COVID-19 pandemic which is transmitted through respiratory route has got global attention and pandemic spread through mass gathering events [29]. As Schuchat [30] reported there are various factors contributed to accelerated spreads of COVID-19 during February-March such as travel, mass gathering, introductions into high-risk work places and densely populated areas and cryptic transmission (Figure 3). For communicable diseases such as COVID-19, mass gathering represents a great challenge to public health and countries. Mass gathering at time of COVID-19 becomes an obstacle to implement social distancing. Since mass gathering is part of citizens' day to day habitual activity, it is inevitable event within one night. For example, various gatherings of persons from different locations, followed by return to their home communities, played a notable role in the early U.S. spread of COVID-19 [30].

After events and gathering they will return to their home with COVID-19 which will be transmitted to the rest family members. Mass gathering is obviously seen in religious beliefs and activities which are also critical in disease spreads such as COVID-19. Religious beliefs and activities are the birth of a new era of both emerging and reemerging diseases that could be arranged under the umbrella of social movements, along with its own role in the spread of zoonotic diseases [31]. Therefore, during this mass congregation disease transmissibility is very high. As travel and urbanization is increasing, the threat of emerging diseases of pandemic potential is increasing along with other endemic diseases [30,32] (Figure 2 and Figure 3 ). As previously mentioned, social distancing in such crowded cities becomes a challenge [29]. For instance, tracing and assessing the suspected individuals in such crowded areas is just like "finding a needle in a haystack" especially this could be the worst for developing nations. If one person is infected by COVID-19 in such a crowded area, then the rate of transmission will be increased by the numbers of contacts (Figure 1) and finally, after so many chains of contacts, COVID-19 will knock out our doors too. This is because the basic reproductive number $(R O)$, for COVID-19 is ex- 
pected to be around 2-3. This meaning, that on average each patient has been spreading infection to 2-3 other people [33]. For example, Figure 1 revealed that each infected person can spread the disease to 2 other people. The other critical problem in densely populated areas is the lack of clean water which increases the transmission of viral diseases. As WHO recommended washing our hands with clean water and other disinfectants is one of the preventive methods for COVID-19, but getting water in such areas might be a challenge for developing countries. Therefore, this becomes an obstacle in preventing the spreads of COVID-19 and other viruses that can be transmitted via contact.

\section{Migration and war}

Migration and war which causes human population movements or upheavals are the critical factors for disease emergence [4]. Migration of humans is the best means for spreading infectious diseases and is inevitable to shape the emergence, frequency, and spread of infections in geographic areas and populations [34]. As example, in Syria millions were displaced, hundreds of thousands gone for goods and the rest were wounded. Beyond such humanitarian crises, the civil war has opened the door for emergence of epidemic of infections that have spread through vulnerable populations in Syria and neighboring countries [35]. According to United Nations High Commissioner for Refugees [36] around 37,000 people a day forced to flee their homes because of conflict and persecution. Therefore, this mass venture leads them to death, to live in refugee tent and to be infected with disease and spread the disease. During these upheavals the rate of disease transmission is paramount and refugee tents could be "disease incubation centers". An immediate and appropriate intervention measures must be taken otherwise those infected individuals could be reservoirs for the virus that can and will re-infect other populations worldwide. Due to the current emerging virus COVID-19 most aid providers may turn face to their internal issues; in this case migrants may face another severe intractable problem. Thus, the global communities should not forget citizens living within a camp otherwise they will go for goods or becomes a source of infection for the rest communities.

\section{Human-animal interaction}

Transmission of viruses from animals to humans is tremendous for emergence or re-emergence of infectious disease. Thus, emerging or re-emerging viral infectious diseases scourges not only human health, but also animal health [37]. Viruses spread without any borders and they jump from animals to humans, and they move from one country to another country [20]. The majority of all human infectious diseases and pandemics have originated through the cross-species transmission of microorganisms from animals to humans [38]. Therefore, the recently emerging pathogens, originate from animals, and continuing disease transmission from animals to human and they became health burden [39]. This issue is more severe in agriculture practice societies because in agrarian nations there is an intimate interaction between animals and humans and animals may

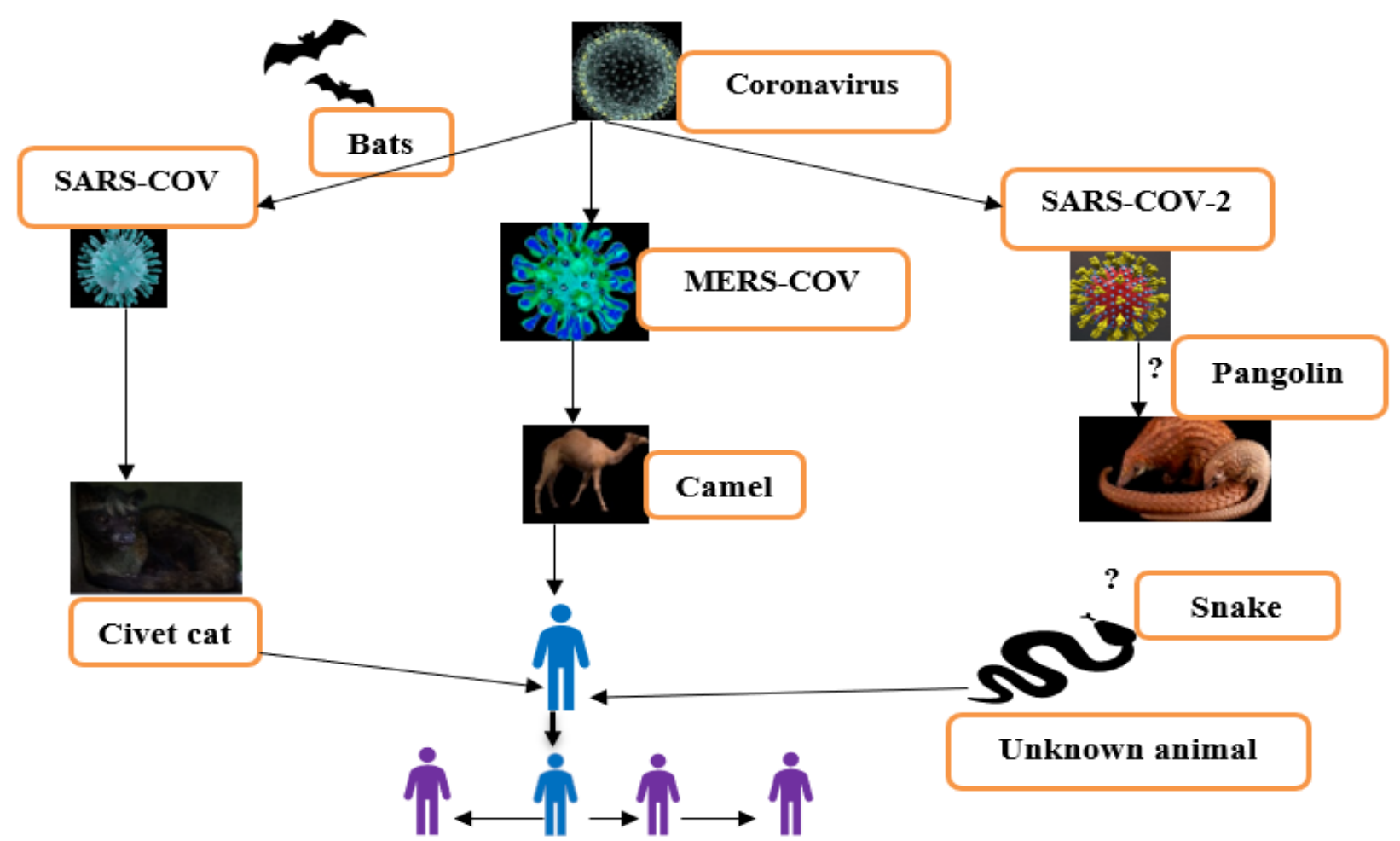

Figure 4: Transmission of coronaviruses and the 2019 novel Coronavirus (2019- nCoV or SARS-CoV-2. According to WHO the real source of SARS-CoV-2 is not known still but some studies have suggested that the intermediate carriers may be snakes or pangolins [44]. 
act as reservoirs of human diseases $[1,40]$. That is why zoonotic virus spillover from wildlife was most frequent in and around human dwellings and in agricultural fields [39]. Besides this, human settlements by itself are conducive for interspecies transmission between farm animals, rodents, dogs, cats and insects [40]. As shown on Figure 4 and Figure 5, there are numbers of zoonotic viruses that can be transmitted from animals or insects to humans. For instance, viruses that originate in bats may be the most notorious emerging zoonoses that spill over from wildlife into domestic animals and humans [23]. Thus, bats are the reservoirs for an array of emerging viruses including coronaviruses (CoVs) that cause serious disease in humans and agricultural animals [41]. As Figure 4 and Figure 5 revealed MERS-CoV is zoonotic virus that can be transmitted from camels to human and this virus is also actively circulates among camels and there is also human-to-human transmission [42]. Some viruses such as coronaviruses ( $\mathrm{CoV}$ ) are frequently shifting hosts, that can be transmitted from animal-to-human (zoonosis), human-to-animal (anthroponotic disease), or animal-to-animal [43]. In support of this notion, MERS-CoV is the best example that can jump from its normal animal host into a human [44] (Figure 4 and Figure 5).

The other contributing factor for viral disease emergence is global or local wildlife trade which is the best means for disease transmission and outbreaks [45]. Illegal trade of bush meat is also paramount for zoonoses to be transferred to the human population. SARS-CoV which was emerged in 2002-2003 and its outbreak was most likely linked to animal markets and history re- peats itself, COVID-19 outbreak is likely related to the seafood market with wildlife trading. However, it is still unknown whether COVID-19 was zoonotically transmitted from an infected civet cat, snake or other animal such as pangolin at the Huanan seafood market [46] (Figure 4). Therefore, it is highly believed that wild animals were involved in the emergence of this contagious virus [47]. Frequent interaction and mixing of different animal species in densely populated areas such as in markets and intrusion human into the natural habitats of animals; have facilitated the emergence of novel viruses [31]. Generally, wild game mammal's interaction in overcrowded cages and unhygienic wet markets allowed the jumping of novel virus from animals to human $[48,49]$. Currently around the globe people have been told to stay at home due to amid COVID-19 but this lockdown order brings a good opportunity for wild animals to venture into urban areas and spill over the deserted roads and cities. As reports revealed in different country roads are invaded by wild animals. This unprecedented event may bring additional health risks. During this animal roaming there might be an interaction between wild and domestic animals which will open for eruption of zoonotic diseases. Perhaps another pandemic may evolve. Therefore, readiness for the known and unknown infectious diseases will be a top priority for our public health systems [26]. For example, COVID-19 emerged in unexpected time, without any preparedness and taking many lives and collapses the global economy. As we are living in unpredictable, environment humans should take lesson from such kinds of horrific events and get ready for next challenges [50].

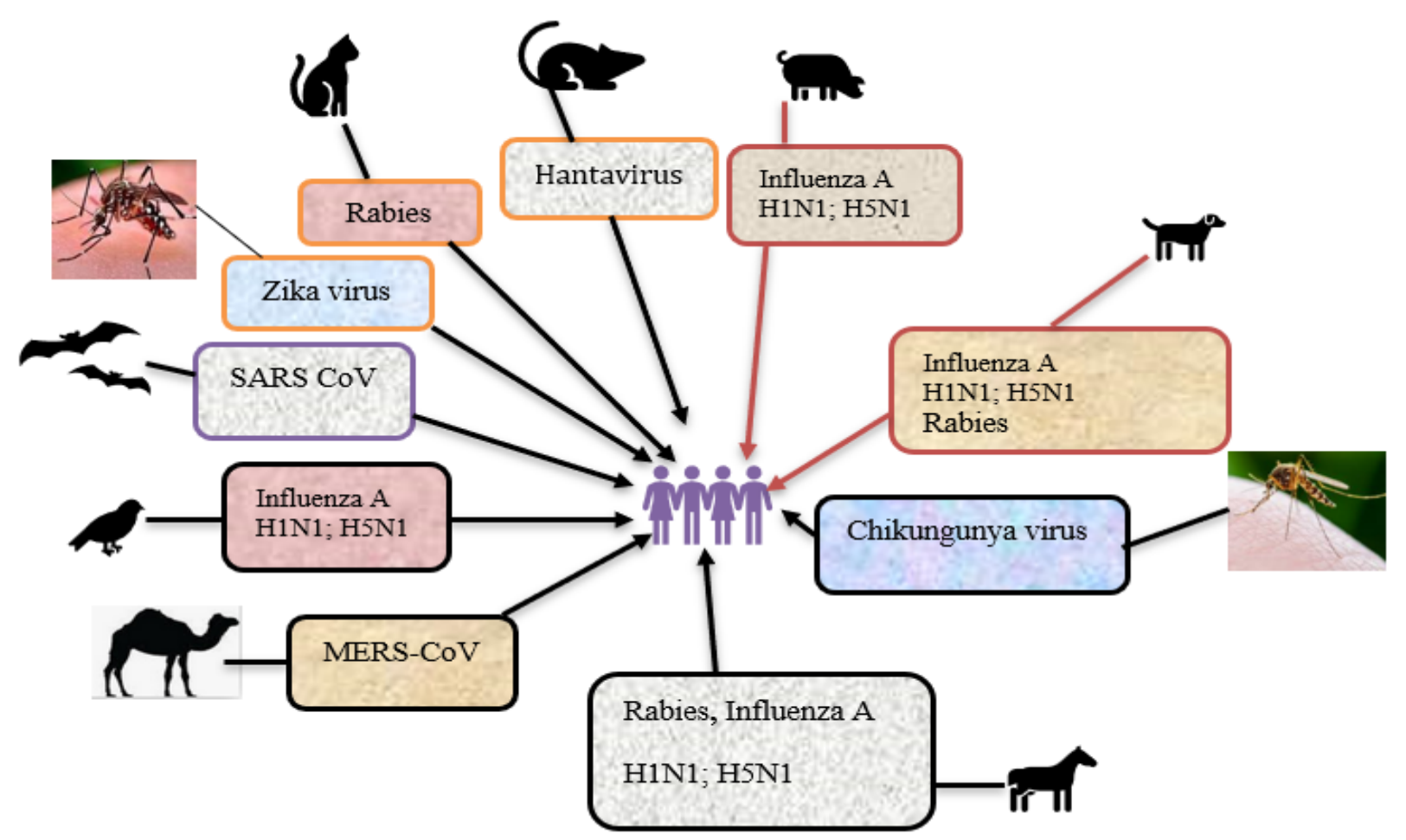

Figure 5: Examples of zoonotic viruses that can be transmitted from animals or insects to humans $[3,15,31,59]$. 


\section{Ecological factors}

As global population is increasing from time to time, land demand is also increasing that put pressure on ecology which leads ecosystem disturbance. Intensive agricultural practice and environmental change were highly related with an increased risk of zoonotic disease emergence [51]. Therefore, the exploitation of nature by humans such as deforestation and/or practice of hunting may put humans into contact with pathogens [52]. Intrusion of human settlements and agriculture on natural ecosystems provides new opportunities for pathogen spillover, genetic diversification, and adaptation. This zone is a critical transition zone where humans, domestic and wild animals are interacting so that zoonotic pathogens may spillover which will be local or global health threat. As Jones, et al. reported loss of biodiversity can aggravate the risk of pathogen spillover [51]. As different studies revealed global or local climate change, disturbance of ecosystems and ecosystem services, large-deforestation, and urbanization as drivers of a wide range of life-threatening infectious diseases [53]. Anthropogenic activities may devastate natural environment and this in turn open a door for emergence or re-emergence of infectious diseases. Therefore, to be healthy, the general wellbeing of plants, animals and our environment should be healthy. This is the general principle of "one health" approach which considers the connections between the environment, plant, animal and human health [54]. Generally, exploiting the natural environments and ecological disturbance along with anthropogenic activities ushered the emergence or re-emergence of viral infectious disease.

\section{Virus related factors}

The other contributing factor in emergence or re-emergence of infectious disease is viral related factor. Pathogens may be prone to emergence in themselves, and rapidly mutating viruses are more common among the emerging pathogens [37]. Viruses can be grouped as DNA or RNA viruses based their genetic material. In terms of stability DNA is more stable than RNA molecule [55] and possessing flexible RNA as a genetic material enables RNA virus to mutate frequently. RNA viruses of plants and animals possess polymerases which are error-prone and produce complex populations of related, but non-identical, genomes called quasispecies [56]. Therefore, upon any harsh environmental conditions such as antiviral stresses, host immune response and treatment of antiviral drugs RNA viruses can mutate or evolve rapidly $[3,57]$. Viruses, particularly RNA viruses, are adept at change and have several mechanisms for altering their genomes [15]. They achieve the high evolution rate through different mechanisms such as mutation, reassortment, and recombination $[3,15]$. Majority life threatening newly emerging viruses are RNA viruses [57]. For instance, mutation and adaptation have driven the co-evolution of coronaviruses (CoVs)
[58]. Coronaviruses are an enveloped RNA virus which have been emerged in different time such as in 2003, 2012 and the current pandemic COVID-19. Pathogenic RNA viruses are potentially the most important group involved in disease transmission from animal to human, and they represent a challenge for global disease control [59]. Generally, a distinctive feature of RNA genomes is the error-prone nature of their replication and retro-transcription [60]. As reports revealed in Chinese wet-markets are potential epicenters for transmission of viral pathogens and new genes might be acquired or existing genes modified through various mechanisms such as genetic reassortment, recombination and mutation [49]. This property of RNA viruses makes them to be a potential pathogen that threatens public health and causes economic recession. For instance, our globe is threatened by COVID-19 and perhaps who knows another novel new coronavirus may evolve in unexpected time.

\section{Coronaviruses}

In human evolution, viruses are serious infectious agents causing a number of life-threatening diseases [3]. Therefore, most of the deadly epidemic and pandemic disease in human history is caused by viral pathogens [13]. Among an innumerable number of viruses, coronaviruses are the hottest issue that scourge human life globally. In the early 1960s, they have been identified and linked to human cattle, pig, and chicken diseases [61]. Several coronaviruses infect an array of different hosts such as cattle (bovine coronavirus (B-CoV), dogs (canine coronavirus (C-CoV)), cats (feline coronavirus $(\mathrm{F}-\mathrm{CoV}))$, and pigs (porcine coronavirus (P-CoV)) [43]. There are around six known human viruses such as human coronaviruses (229E, NL63, OC43, HKU1), SARSCoV and MERS-CoV [62]. For instance, in 2003 Severe Acute Respiratory Syndrome outbreak has occurred and was caused by newly emerged SARS-associated coronavirus (SARS-CoV). And again in 2012, another dangerous disease called Middle East respiratory syndrome was emerged and was caused by novel coronavirus called Middle East respiratory syndrome coronavirus (MERS-CoV) [63]. The MERS-CoV outbreak in Saudi Arabia is probably one of the most challenging threats to national and international public health [64]. Now on $31^{\text {st }}$ December 2019, at Wuhan city, Hubei Province, in China new case of pneumonia of unknown etiology was detected and the World Health Organization (WHO) was alerted about this unprecedented etiology. After identifying more cases from patients, then they confirmed that the infectious agent was novel coronavirus (COVID-19) [29,65]. The current emerged novel human coronavirus, SARS-CoV-2, has become a global health challenge causing severe respiratory tract infections in humans [66]. This deadly and contagious viral disease continues to take lives globally. We human beings are "invaded" by COVID-19 pandemic which declares dev- 


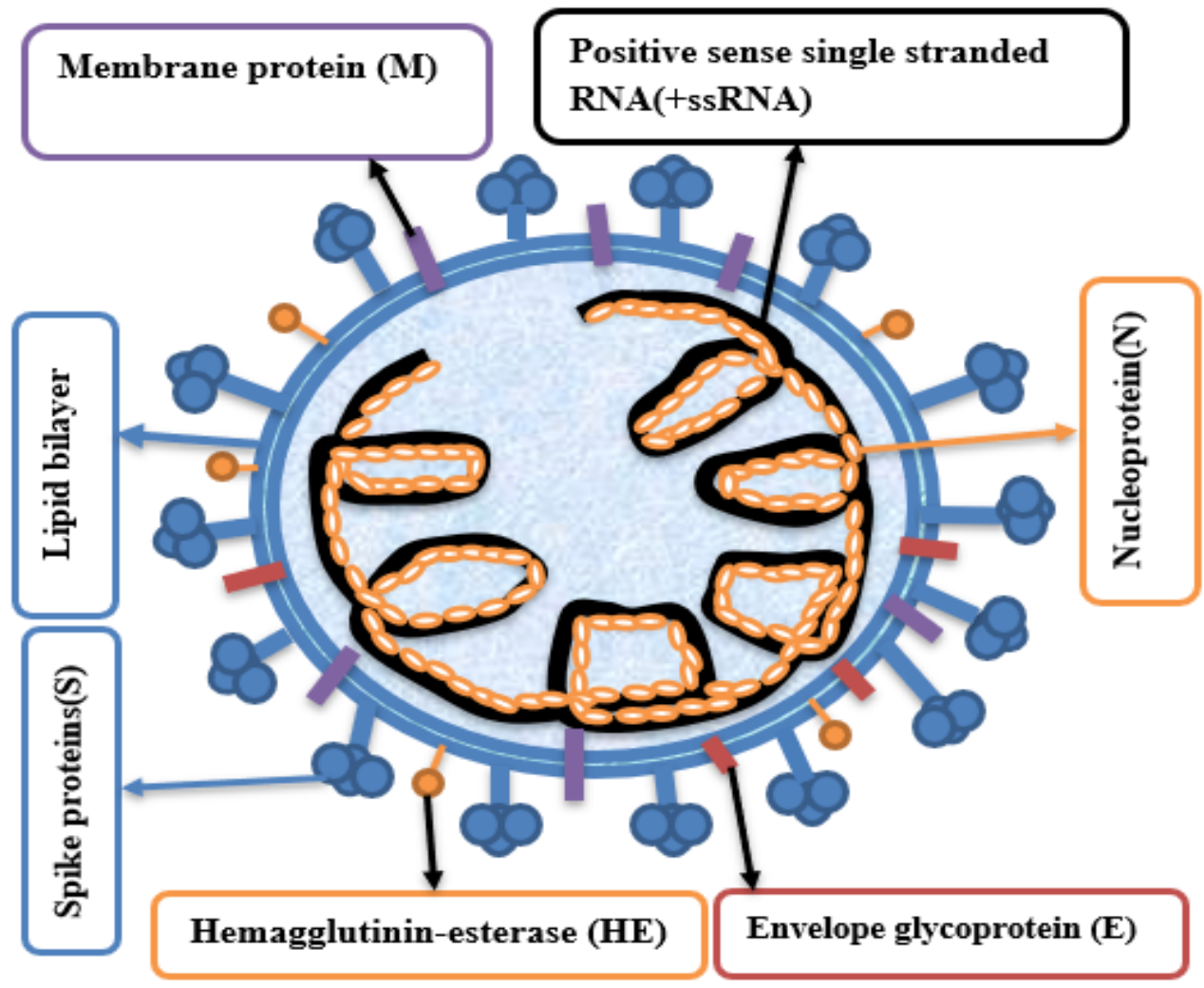

Figure 6: Coronavirus structure adapted from [75] with major own modification.

astating "war" on us and detained us to stay at home forcibly. Therefore, it is possible to say that our globe is under viral war.

\section{Biology of coronaviruses}

Coronaviruses are enveloped helical viruses with large, positive sense, single-stranded RNA (+ ssRNA) genome and contain club-shaped surface proteins called spikes on their surfaces which give the virus particles the appearance of a solar corona in which the virus gets its name. Coronaviruses belong to the Coronaviridae family of the Nidovirales order [67-71]. Coronavirus virions are spherical overall but the RNA genome inside is arranged in a flexible helical structure, closely bound to a nucleocapsid protein [72] (Figure 6). As shown on Figure 6 RNA (black color) is associated with nucleoprotein (orange color). Most RNA viruses are deadly pathogens since they evolve rapidly in any hostile conditions and exhibit error-prone gene replication [3]. If the virus continuously mutates, recombines or reassorts, then human health will be scourged. This is because the virus will be emerged in unexpected time with unknown "weapons" and mysterious behavior and this in turn will be new or unknown for immune cells which are our "soldiers" and as well as medication. Therefore, understanding its obscure behavior and developing vaccines or antiviral drugs needs time, but within this time gap lives of millions will be lost. That is why we are wrestling with COVID-19 a current global health threat and future fear of public health, because everything is on its own hand and it might be more aggressive. Several human pathogenic viruses are enveloped possessing lipid bilayer which acts as an additional protective coat and infects their target cells by inducing the fusion of the viral envelope with the cell membrane [73]. Therefore, this lipid-containing membrane surrounds some virus particles and surfaces proteins are protrude from this membrane (Figure 6). As shown in Figure 6 Coronavirus virions contain structural proteins such as spike glycoprotein (S), envelope glycoprotein (E), membrane glycoproteins $(\mathrm{M})$, and nucleoprotein $(\mathrm{N})$. Besides these structural proteins, some coronaviruses such as betacoronaviruses have the second fringe of shorter spikes called hemagglutinin which has enzymatic activities (Figure 6). Therefore, they contain receptor-destroying enzymes that exhibit acetylesterase, as well as receptor-binding activity. Because of these activities and properties, they are termed as hemagglutinin-esterases (HEs) [74]. All these structural proteins have their own roles in attachment, fusion, assembly, maturation, and other viral related activities. Viruses have different mechanisms for entrance into their host. For example, enveloped viruses enter cells by inducing fusion of viral and cellular membranes, and this step is assisted or catalyzed by a specialized membrane-fusion protein expressed on their surface [73]. Therefore, the viral infection is mainly dependent on surface structures such as spikes that determine host, cell, and tissue tropism.

As shown in Figure 6 spikes (S) are the forefront and "right-hand" of enveloped viruses that are important for attachment and interaction with host receptor molecules. The distinctive features of surface spikes of 
coronaviruses are composed of trimers of S molecules [75] (Figure 6). These widely spaced spikes found on the envelope of coronaviruses are the key structures important to species tropism, tissue tropism, pathogenesis in the host, and the ability to cross between species [67]. The coronavirus spike protein is a multifunctional molecular machine that mediates coronavirus entry into host cells [76]. As previously mentioned, RNA virus can evolve either through mutation, reassortment, or recombination, and in this case the virus may generate unique surface proteins, spikes that worsen medication. The other structural protein is M protein which plays an astonishing role in virus assembly, turning cellular membranes into workshops where virus and host factors come together to make new virus particles [77]. Both $\mathrm{M}$ and $\mathrm{E}$ are involved in the assembly of the coronavirus envelope [78]. In terms of number $M$ proteins are the most abundant structural protein. The other structural protein that binds genomic RNA is nucleoprotein which interacts with the viral membrane protein during virion assembly and plays a critical role in enhancing the efficiency of virus transcription and assembly [79]. Additionally, the coronavirus nucleocapsid $(N)$ protein forms a helical ribonucleoprotein with the viral positive-strand RNA genome [80]. Generally, knowing viral structure is essential for a better understanding of the possibility of virus transfer and cross-contamination, and for formulating appropriate infection-control measures [6] and even designing appropriate antivral drugs and vaccines.

\section{Route of spread}

Coronaviruses are spread by the respiratory route. For instance, severe acute respiratory syndrome (SARS) is caused by SARS coronavirus (SARS CoV), which is spread by the respiratory route and through the ingestion of aerosolized faeces via contamination of the hands and environment. Close contact with a symptomatic person poses the highest risk of infection [81]. Many people remain asymptomatic after being infected with SARS-CoV. But, in individuals who do develop symptoms, a dry cough and labored breathing are common. Similarly, COVID-19 infected individuals show fever, cough, and shortness of breath [82]. Asymptomatic cases the most dangerous and hidden scenario in which viruses can spread from asymptomatic persons to susceptible individuals [30]. According to the reports of CDC, SARS can be spread from one person to the other by close contact, and touching eyes, nose, and mouth with the contaminated hand is the main route for transmission [83]. Besides this, contaminated fomite that has contact with droplets from coughing or sneezing is also a source of contamination. Generally, human coronaviruses spread by coughing, sneezing, and close personal contact, such as touching mouth, nose, or eyes or shaking bands. That is why social-distance and hand-washing are advocated everywhere. MERS-CoV is transmitted from dromedary camels to humans and occasionally through human-to-human contact [42] (Figure 4 and Figure 5). The newly emerged virus is also spread via droplet transmission when a person is in close contact with someone who has respiratory symptoms (e.g., coughing or sneezing) and is therefore at risk of when there is contact with his/her mouth, nose or eyes. There might be also transmission through fomites which has contact with infected person. Therefore, COVID-19 is spread through close person-to-person contact by touching one's eyes, nose, or mouth after contact with COVID-19. The novel coronavirus 2019-nCoV has an array of biological and epidemiological characteristics, making it more contagious than previously emerged SARS-CoV and MERS-CoV [84]. As an example, on Figure 1 , one person can infect averagely two people and continues in exponential fashion. So, this figure shows that COVID-19 is a highly contagious viral disease. For such kinds of contagious viral disease congregation in different areas for a different purpose is just like adding flammable gas to fire. As Shim, et al. reported the transmission of SARS-CoV-2 in Korea in confined settings, including a hospital and a church in the city of Daegu is very high [85].

\section{At-risk groups}

Old aged individuals are more susceptible to coronavirus infection. The most severe and fatal infections with SARS have been in elderly persons [81]. Similarly, WHO reported that older people, immune-compromised individuals and those with underlying medical problems like cardiovascular disease, diabetes, chronic respiratory disease, and cancer are more likely susceptible to COVID-19. Even if elderly individuals with other health complaints are more severely affected, COVID-19 is also health issue of the rest age groups. Most people infected with the COVID-19 virus will experience mild to moderate respiratory illness and recover without requiring special treatment [29]. However, for severe cases with insufficient oxygen reaching the blood, patients require mechanical ventilation. But getting sufficient number of mechanical ventilators is also another critical problem besides health issue. Coronavirus Disease 2019 (COVID-19) threatens to overwhelm medical infrastructure causing spikes in mortality rates because of shortages of critical equipment, like ventilators [86]. Countries with fragile health system may face the shortage of mechanical ventilators especially developing nations who can't afford to buy even gloves and masks become a major problem during this panic and pandemic.

\section{Infection control}

Infection control is not the issue of a single country rather it is an issue of global community. Thus, controlling the spread of emerging and re-emerging viruses requires international efforts and collaboration [20]. As recommended by WHO the spread of coronaviruses can be reduced by hand-washing after patient contact. Besides hand-washing the use of gloves, face masks, aprons, goggles, and respirators by healthcare workers 
will also reduce the risk of transmission. Isolation in single rooms or cohort nursing reduces the risk to other patients [81]. Generally, WHO recommend the following controlling measures for COVID-19 such as isolation of patients, quarantine of exposed people, travel restriction, massive screening, avoiding contact with infected people or sharing utensils with infected people $[29,30]$. If the reservoir host is also known, avoiding contact with that specific host will reduce the risk of transmission. Besides these preventive measures personal commitment to obey and apply preventive methods recommended by WHO or health professionals are tremendous to save our lives and the lives of others. For instance, there are some patients who consider quarantine or isolation as "hell" so that they either escape or hide themselves which is risky event for the rest of other community. Therefore, there must be awareness creation on self-revealing and isolation to save the lives of others. In general, controlling an emerging virus such as COVID-19 is as difficult as controlling wild fire. Wildfire can be controlled or extinguished at its infant stage or on that starting spot otherwise it will be difficult to control once and for all unless it damages everything around there. Mass mobility in overcrowded area, seating in groups, public meeting and other group activities are considered just like adding flammable gas to fire. Therefore, all these will facilitate the expansion of the virus. If the origin of virus is known and including its mode of transmission, then this will be the right place and time to extinguish the "fire". This is what our globe is facing to extinguish COVID-19 which is an expanding global inferno. To control fire removing materials around onset of the fire and put away from that area are tremendous in lowering the expansion and rescuing either lives or materials. This analog is similar to social distancing and staying at home saves lives from global inferno (COVID-19). Therefore, staying away from this fire (COVID-19) and social distancing are the best preventive methods. On this preventive principles Chinese are the best global example in controlling pandemic COVID-19 at Wuhan city and the rest areas. The WHO recommended staying at home to control the spreads of this contagious virus. However, it might be difficult to adopt this recommendation for those individuals who are running and working for their daily or handto-mouth consumption. The other problem to control this emerging virus is unable to apply rules ratified or recommended by WHO or by each respective country. Here discipline and behavioral change are the key means to defeat COVID-19. However, there are some individuals who are scoffing at social distancing or stay at home principles. Hence, unable to implement these and other health principles for COVID-19 is just like playing with "fire" and the fate is obvious as we have seen in different parts of our world. So, there must be awareness creation on social responsibility to reveal and quarantine her/him when there is suspicion to save the lives of others. As an example, if the man indicated on Figure 1 was isolated and quarantined, then those 62 people wouldn't be infected by this contagious virus. Therefore, the letters $(A, B, C, D$, and $E$ ) indicated on Figure 1 are preventive and isolation measures that can interrupt the chain of person-to-person infection. Generally, to control the spreads of COVID-19 and other contagious viral disease there must be collaboration at individual, family, village, local, regional, country and global level. As we know our personal interest is never contented, therefore we should limit our interest and control ourselves to save the lives of others and ourselves from COVID-19.

\section{Conclusion and Recommendation}

Although there is progress in the area of medical sector, the emergence or re-emergence of novel pandemic viruses remains an enduring problem in human health, global economy, social instability, and insecurity worldwide. As COVID-19 revealed the global health system is not sufficient enough to handle pandemics. For immediate intervention knowing the source of pandemic is a cornerstone but there some difficulties on this issue. Even though there are some speculations, our globe is still searching the exact source of COVID-19 pandemic. This is also another gap in global health system. Human, environmental and viral related factors are risky factors involved in the emergence or re-emergence of viral infectious diseases or spreads of disease. Therefore, knowing or tracing these contributing risk factors is pivotal in disease surveillance, mitigating the problem, suggesting preventive and control methods for viral infectious diseases. Among many innumerable numbers of viruses, coronaviruses are the hottest issue that scourges human life globally. Possessing RNA as genetic material for viruses is challenging problem in medical sector. This is because RNA viruses are evolving rapidly in any hostile conditions and exhibit error-prone gene replication. In human history, Coronaviruses were emerged unexpectedly and at unpredicted time. The current COVID-19 pandemic emerged at Wuhan city becomes a global health problem. This newly emerged viral disease has an impact on the economy, health, tourism, social interaction, politics, education, religion, labor, entertainment, sport, markets, hotels, transportation and human freedom. This global health problem needs global collaboration to control otherwise it will circulate within a community for long periods.

Therefore, the following recommendations are forwarded based on the above review paper:

- Tracing and knowing the contributing risk factors for emergence or re-emergence of viral infectious disease must be a top priority. This is because they can act as a compass in providing appropriate information on preventive and controlling methods. Tracing the source of the disease and taking appropriate 
measures at its onset is the forefront step in disease control. This is because searching the source of a virus can ushered us to very simple interventions. For instance, there is speculation on source of COVID-19 but the exact source is still unknown.

- Disease surveillance system must be implemented since it is an eye for health system in giving information on preventive and controlling approaches, otherwise everything will be blind. There should be fast disease reporting system that allows health experts to have reliable information on that specific outbreak and apply control strategies.

- Viral infectious disease such as COVID-19 don't know any border, within a short period of time, it becomes global issue. Since we are all in the same boat, global community must collaborate to extinguish the "inferno" at its infant stage, otherwise death toll will continue. This is the right time and event in which mankind should learn the importance of unification to defeat both natural and man-made disasters.

- Arrays of viruses are animal origin and circulate in wild and domestic animals. Domestic and wild animal reservoirs should be under surveillance that includes diversity, species implicated, and geographical distribution. Additionally, illegal wild animal trade should be controlled. For instance, pangolins are 'the most illegally traded mammal in the world' and are suspected as a potential coronavirus host. Therefore, spillover of a virus from animals to humans should be prevented and controlled to save billions of dollars and human lives. Generally, each respective country should develop and ratify a series of laws and regulations for the prevention and control of infectious diseases in humans, domestic animals, and wild animals.

- The global community should learn something from COVID-19. As this pandemic revealed the global health system is not sufficient enough to handle such kinds of contagious viral disease. Therefore, we have to learn from this challenge and sew gaps and get ready for the next challenges. This because we don't know when and where the next pandemic will emerge.

- The preventive and controlling methods forwarded by WHO or other concerned body should be followed and applied strictly. Therefore, there must be a continuous awareness creation on preventive and controlling methods along with obeying rules ratified by each respective country in time of such pandemics.

\section{Data Availability}

The data used to support the findings of this study are available from the corresponding author upon request.

\section{Conflicts of Interest}

I declare that there are no conflicts of interest in regard to the publication of this paper.

\section{Acknowledgments}

The author would like to thank Wolaita Sodo University but no fund is taken to conduct this review paper.

\section{References}

1. Parvez MK, Parveen S (2017) Evolution and emergence of pathogenic viruses: Past, present, and future. Intervirology 60: 1-7.

2. Mandyata CB, Olowski LK, Mutale W (2017) Challenges of implementing the integrated disease surveillance and response strategy in Zambia: A health worker perspective. BMC Public Health 17: 746.

3. Jaijyan DK, Liu J, Hai R, Zhu H (2018) Emerging and reemerging human viral diseases. Ann Microbiol Res 2: 31-44.

4. Morse SS (1995) Factors in the emergence of infectious diseases. Emerg Infect Dis 1: 7-15.

5. Quaglio G, Demotes-Mainard J, Loddenkemper R (2012) Emerging and re-emerging infectious diseases: A continuous challenge for Europe. Eur Respir J 40: 1312-1314.

6. Geller C, Varbanov M, Duval RE (2012) Human coronaviruses: Insights into environmental resistance and its influence on the development of new antiseptic strategies. Viruses 4: 3044-3068.

7. World Health Organization (WHO) (2014) A brief guide to emerging infectious diseases and zoonoses.

8. Wigginton KR, Ye Y, Ellenberg RM (2015) Emerging investigators series: The source and fate of pandemic viruses in the urban water cycle. Environ Sci Water Res Technol 1: 735-746.

9. Nii-Trebi NI (2017) Emerging and neglected infectious diseases: Insights, advances, and challenges. Bio Med Res Int 5245021.

10. Lashley FR (2003) Factors contributing to the occurrence of emerging infectious diseases. Biol Res Nurs 4: 258-267.

11. Graham RL, Deming DJ, Deming ME, Yount BL, Baric RS (2018) Evaluation of a recombination-resistant coronavirus as a broadly applicable, rapidly implementable vaccine platform. Commun Biol 1: 179.

12. Mahon CR, Lehman DC, Manuselis G (2011) Textbook of diagnostic microbiology, WB Saunders Company, 3251 Riverport Lane, Maryland Heights, Missouri 63043.

13. Mourya DT, Yadav PD, Ullas PT, Bhardwaj SD, Sahay RR, et al. (2019) Emerging/re-emerging viral diseases \& new viruses on the Indian horizon. Indian J Med Res 149: 447-467.

14. Louten J (2016) Essential Human Virology. ( $1^{\text {st }}$ edn), Sara Tenney, UK, USA.

15. Griffin DE (2010) Emergence and re-emergence of viral diseases of the central nervous system. Prog Neurobiol 91: 95-101.

16. Bedford J, Farrar J, Ihekweazu C, Kang G, Koopmans M, et al. (2019) A new twenty-first century science for effective epidemic response. Nature 575: 130-136.

17. Morens DM, Fauci AS (2013) Emerging Infectious diseases: Threats to human health and global stability. PLoS Pathog 9: e1003467. 
18. Morse SS (2007) Global infectious disease surveillance and health intelligence. Health Aff 26: 1069-1077.

19. Nadeem MS, Zamzami MA, Choudhry H, Murtaza BN, Kazmi I, et al. (2020) Origin, potential therapeutic targets and treatment for coronavirus disease (COVID-19). Pathogens 9: 307.

20. Liu SL, Saif L (2020) Emerging viruses without borders: The Wuhan coronavirus. Viruses 12: 130.

21. Yale G, Bhanurekha V, Ganesan PI (2013) Anthropogenic factors responsible for emerging and re-emerging infectious diseases. Current Science 105: 940-946.

22. Mackey TM, Liang BA, Cuomo R, Hafen R, Brouwer KC, et al. (2014) Emerging and reemerging neglected tropical diseases: A review of key characteristics, risk factors, and the policy and innovation environment. Clin Microbiol Rev 27: 949-979.

23. Plowright RK, Eby P, Hudson PJ, Smith IL, Westcott D, et al. (2015) Ecological dynamics of emerging bat virus spillover. Proc R Soc B 282: 20142124.

24. Mangy CD, Manyama CK, Sudi L, Sabi I, Msila H, et al. (2016) Emerging viral infectious disease threat: Why Tanzania is not in a safe zone. Tanzania Journal of Health Research 18 .

25. Buliva E, Elhakim M, Tran Minh NN, Elkholy A, Mala P, et al. (2017) Emerging and reemerging diseases in the world health organization (WHO) eastern mediterranean region-progress, challenges, and $\mathrm{WHO}$ initiatives. Front Public Health 5: 276.

26. Gupta SK, Gupta P, Sharma P, Shrivastava AK, Soni SK (2012) Emerging and Re-emerging Infectious Diseases, future challenges and strategy. J Clin Digno Resear 6: 10951100.

27. Chowell G, Abdirizak F, Lee S, Lee J, Jung E, et al. (2015) Transmission characteristics of MERS and SARS in the healthcare setting: A comparative study. BMC Med 13: 210.

28. Lee A (2020) Wuhan novel coronavirus (COVID-19): Why global control is challenging?. Public Health 179, A1-A2.

29. World Health Organization (WHO) (2020) Novel coronavirus (2019-nCoV) situation report -1 (website).

30. Schuchat A (2020) Public health response to the initiation and spread of pandemic COVID-19 in the United States, February 24-April 21, 2020. MMWR Morb Mortal Wkly Rep 69: $551-556$

31. Al-Tayib OA (2019) An overview of the most significant zoonotic viral pathogens transmitted from animal to human in Saudi Arabia. Pathogens 8: 25.

32. Nsubuga $P$, Nwanyanwu $O$, Nkengasong JN, Mukanga $D$, Trostle M (2010) Strengthening public health surveillance and response using the health systems strengthening agenda in developing countries. BMC Public Health 10: S5.

33. Liu Y, Gayle AA, Wilder-Smith A, Rocklöv J (2020) The reproductive number of COVID-19 is higher compared to SARS coronavirus. J Travel Med 27.

34. Wilson ME (1995) Travel and the emergence of infectious diseases. Emerg Infect Dis 1: 39-46.

35. Sharara SL, Kanj SS (2014) War and infectious diseases: Challenges of the Syrian civil war. PLoS Pathog 10 : e1004438.

36. United Nations High Commissioner for Refugees (2018) UNHCR's global trends in forced displacement in 2018.
37. Lindahl JF, Grace D (2015) The consequences of human actions on risks for infectious diseases: A review. Infect Ecol Epidemiol 5: 30048.

38. Pike BL, Saylors KE, Fair JN, LeBreton M, Tamoufe U, et al. (2020) The origin and prevention of pandemics. Clin Infect Dis 50: 1636-1640.

39. Johnson CK, Hitchens PL, Evans TS, Goldstein T, Thomas $\mathrm{K}$, et al. (2015) Spillover and pandemic properties of zoonotic viruses with high host plasticity. Sci Rep 5: 14830

40. Howard CR, Fletcher NF (2012) Emerging virus diseases: Can we ever expect the unexpected? Emerg Microbes Infect 1: e46.

41. Banerjee A, Kulcsar K, Misra V, Frieman M, Mossman K (2019) Bats and Coronaviruses. Viruses 11: 41.

42. Killerby ME, Biggs HM, Midgley CM, Gerber SI, Watson JT (2020) Middle east respiratory syndrome coronavirus transmission. Emerg Infect Dis 26: 191-198.

43. Graham RL, Baric RS (2010) Recombination, reservoirs, and the modular spike: Mechanisms of coronavirus cross-species transmission. J Virol 84: 3134-3146.

44. Nguyen T, Bang DD, Wol A (2020) 2019 novel coronavirus disease (COVID-19): Paving the road for rapid detection and point-of-care diagnostics. Micromachines 11: 306.

45. Karesh WB, Cook RA, Bennett EL, Newcomb J (2005) Wildlife trade and global disease emergence. Emerg Infect Dis 11: 1000-1002.

46. Peeri NC, Shrestha N, Rahman Md S, Zaki R, Tan Z, et al. (2020) The SARS, MERS and novel coronavirus (COVID-19) epidemics, the newest and biggest global health threats: What lessons have we learned?. Int J Epidemiol.

47. Sun J, He W, Wang L, Zhou J, Viet M, et al. (2020) COVID-19: Epidemiology, evolution, and cross-disciplinary perspectives. Trends in Molecular Medicine 26: 483-495.

48. Webster RG (2004) Wet markets-A continuing source of severe acute respiratory syndrome and influenza?. Lancet 363: 234-236.

49. Woo PCY, Lau SKP, Yuen KY (2006) Infectious diseases emerging from Chinese wet-markets: Zoonotic origins of severe respiratory viral infections. Curr Opin Infect Dis 19: 401-407.

50. Meerburg BG, Singleton GR, Kijlstra A (2009) Rodent-borne diseases and their risks for public health. Crit Rev Microbiol 35: $221-270$

51. Jones BA, Grace D, Kock R, Alonso S, Rushton J, et al. (2013) Zoonosis emergence linked to agricultural intensification and environmental change. PNAS 110: 8399-8404.

52. Devaux CA (2012) Emerging and re-emerging viruses: A global challenge illustrated by chikungunya virus outbreaks. World J Virol 1: 11-22.

53. Nava A, Shimabukuro JS, Chmura AA, Luz SLB (2017) The impact of global environmental changes on infectious disease emergence with a focus on risks for Brazil. ILAR J 58: 393-400.

54. Ruscio BA, Brubaker M, Glasser J, Hueston W, Hennessy TW (2015) One Health - A strategy for resilience in a changing arctic. Int J Circumpolar Health 74: 27913.

55. Szabat M, Kierzek R (2017) Parallel-stranded DNA and RNA duplexes-structural features and potential applications. FEBS J 284: 3986-3998. 
56. Novella IS, Presloid JB, Taylor RT (2014) RNA replication errors and the evolution of virus pathogenicity and virulence. Current Opinion in Virology 9: 143-147.

57. Ryu WS (2017) Other negative-strand RNA viruses. Molecular Virology of Human Pathogenic Viruses 2017: 213-224.

58. Ye ZW, Yuan S, Yuen KS, Fung SY, Chan CP, et al. (2020) Zoonotic origins of human coronaviruses. Int J Biol Sci 16 : 1686-1697.

59. Carrasco-Hernandez R, Jácome R, Vidal YL, León SPD (2017) Are RNA viruses candidate agents for the next global pandemic? A Review. ILAR J 58: 343-358.

60. Domingo E, Escarmís C, Sevilla N, Moya A, Elena SF, et al. (1996) Basic concepts in RNA virus evolution. FASEB $J$ 10: 859-864

61. Acheson NH (2011) Fundamentals of molecular virology. ( $2^{\text {nd }}$ edn), John Wiley \& Sons, Inc. 111 River Street, United States.

62. Apurba SS, Sandhya BK (2016) Essentials of medical microbiology, the health sciences publisher, New Delhi, London, Philadelphia, Panama.

63. Talaro KP, Chess B (2015) Foundations in microbiology. ( $9^{\text {th }}$ edn), Published by McGraw-Hill Education, 2 Penn Plaza, New York, NY 10121.

64. Al-Rabiaah A, Temsah MH, Al-Eyadhy AA, Hasan GM, Al-Zamil F, et al. (2020) Middle east respiratory syndrome-corona virus (MERS-CoV) associated stress among medical students at a university teaching hospital in Saud Arabia. J Infect Public Health 13: 687-691.

65. Adhikari S, Meng S, Wu YJ, Mao YP, Ye RX, et al. (2020) Epidemiology, causes, clinical manifestation and diagnosis, prevention and control of coronavirus disease (COVID-19) during the early outbreak period: A scoping review. Infect Dis Poverty 9: 29.

66. Kampf G, Todt D, Pfaender S, Steinmann E (2020) Persistence of coronaviruses on inanimate surfaces and their inactivation with biocidal agents, J Hosp Infect 104: 246251.

67. Wang Q, Vlasova AN, Kenney SP, Saif LJ (2019) Emerging and re-emerging coronaviruses in pigs, Curr Opin Virol 34: 39-49.

68. Schoeman D, Fielding BC (2019) Coronavirus envelope protein: Current knowledge. Virol J 16: 69.

69. Flint J, Racaniello VR, Rall GF, Skalka AM, Enquist LW (2015) Principles of Virology. (4 ${ }^{\text {th }}$ edn), American Society for Microbiology press, Washington, DC.

70. Dimmock NJ, Easton AJ, Leppard KN (2007) Introduction to Modern Virology. ( $7^{\text {th }}$ edn), Blackwell publishing, USA, UK, Australia.
71. Forni D, Cagliani R, Clerici M, Sironi M (2017) Molecular evolution of human coronavirus genomes, Trends in Microbiology 25: 35-48.

72. Lostroh P (2019) Molecular and cellular biology of viruses. $\left(1^{\text {st }}\right.$ edn), Taylor \& Francis Group, LLC, Boca Raton.

73. Rey FA, Lok SM (2018) Common features of enveloped viruses and implications for immunogen design for next-generation vaccines. Cell 172: 1319-1334.

74. Klausegger A, Strobl B, Regl G, Kaser A, Luytjes W, et al. (1999) Identification of a coronavirus hemagglutinin-esterase with a substrate specificity different from those of influenza c virus and bovine coronavirus. J Virol 73: 3737-3743.

75. Weiss SR, Leibowitz JL (2011) Coronavirus pathogenesis. Adv Virus Res 81: 85-164.

76. Li F (2016) Structure, function, and evolution of coronavirus spike proteins. Annu Rev Virol 3: 237-261.

77. Neuman BW, Kiss G, Kunding AH, Bhella D, Baksh MF, et al. (2011) A structural analysis of $M$ protein in coronavirus assembly and morphology, J Struct Biol1 74: 11-22.

78. Haan CAMD, Vennema H, Rottier PJM (2000) Assembly of the coronavirus envelope: Homotypic interactions between the $\mathrm{m}$ proteins. J Virol 74: 4967-4978.

79. McBride R, Van Zyl M, Fielding BC (2014) The coronavirus nucleocapsid is a multifunctional protein. Viruses 6: 29913018.

80. Kuo L, Koetzner CA, Hurst KR, Masters PS (2014) Recognition of the murine coronavirus genomic RNA packaging signal depends on the second RNA-binding domain of the nucleocapsid protein, J Virol 88: 4451-4465.

81. Kudesia G, Wreghitt T (2009) Clinical and Diagnostic Virology, Cambridge University Press, Cambridge, New York, Melbourne, Madrid, Cape Town, Singapore, São Paulo.

82. Centers for Disease Control and Prevention (CDC) (2020) Coronavirus Disease 2019 (COVID-19).

83. Centers for Disease Control and Prevention (CDC) (2004) Severe acute respiratory syndrome.

84. Meo SA, Alhowikan AM, Al-khlaiwi T, Meo IM, Halepoto DM, et al. (2020) Novel coronavirus 2019-nCoV: Prevalence, biological and clinical characteristics comparison with SARS-CoV and MERS-CoV. Eur Rev Med Pharmacol Sci 24: 2012-2019.

85. Shima E, Tariq A, Choi W, Lee Y, Chowell G (2020) Transmission potential and severity of COVID-19 in South Korea. International Journal of Infectious Diseases 93: 339-344.

86. Pearce JM (2020) A review of open source ventilators for COVID-19 and future pandemics. F1000 Res 9: 218. 